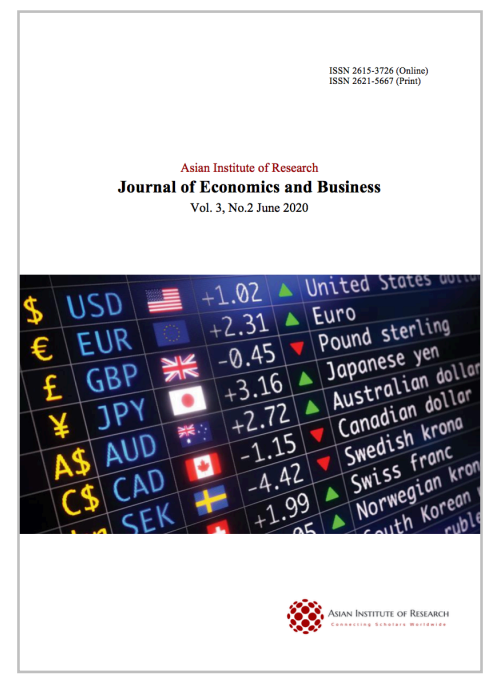

\title{
Journal of Economics and Business
}

\section{Tamanna, Tabassum. (2020), Consumer Perceptions and Expectations of Service Quality: Assessment through SERVQUAL Dimensions. In: Journal of Economics and Business, Vol.3, No.2, 483-488.}

ISSN 2615-3726

DOI: 10.31014/aior.1992.03.02.213

The online version of this article can be found at: https://www.asianinstituteofresearch.org/

Published by:

The Asian Institute of Research

The Journal of Economics and Business is an Open Access publication. It may be read, copied, and distributed free of charge according to the conditions of the Creative Commons Attribution 4.0 International license.

The Asian Institute of Research Journal of Economics and Business is a peer-reviewed International Journal. The journal covers scholarly articles in the fields of Economics and Business, which includes, but not limited to, Business Economics (Micro and Macro), Finance, Management, Marketing, Business Law, Entrepreneurship, Behavioral and Health Economics, Government Taxation and Regulations, Financial Markets, International Economics, Investment, and Economic Development. As the journal is Open Access, it ensures high visibility and the increase of citations for all research articles published. The Journal of Economics and Business aims to facilitate scholarly work on recent theoretical and practical aspects of Economics and Business. 


\title{
Consumer Perceptions and Expectations of Service Quality:
}

\section{Assessment through SERVQUAL Dimensions}

Tabassum Tamanna ${ }^{1}$

${ }^{1}$ MPhil Researcher, Bangladesh University of Professionals (BUP), Mirpur Cantonment, Road-2 Section-12, Dhaka-1216. Email address: tanni.kapil@gmail.com

\begin{abstract}
Service quality is very important to attract and retain customers in today's competitive business environment. Using the SERVQUAL model this research evaluates customers' expectations against their perceptions of the service quality in a private financial institute at Dhaka city of Bangladesh. To measure respondent's satisfaction level with the provided service quality of financial institutes. Fifty (50) clients were interviewed where the sample was selected non-randomly. The results showed that respondents' expectations and perception level markedly varied with the service provided by a financial institution. However, SERVQUAL tangible dimension indicated a small gap between expectation and perception level. The study concluded that level of customers' expectations on the service quality from any private financial service providers was higher than they perceived earlier. Customer services of private financial institutes should improve further through high quality services to achieve their optimum level of businesses.
\end{abstract}

Keywords: Customer, Expectation, Perception, Satisfaction, SERVQUAL

\section{Introduction}

In today's competitive business environment, service quality is very important to attract and retain customers as customers derive their perceptions of service quality on the levels of satisfaction they experience with a particular business. Businesses need to be able to satisfy customers and meet their expectations of service quality in order to gain competitive advantage (Gagliano, K.B. \& Hathcote, J., 1994). Thus marketers need to continually assess customers' expectations of service quality in order to avoid customer dissatisfaction (Zeithaml, V.A. and Bitner, M.J., 1996). A service can be offered by any business, whose main aim is to meet or satisfy customer needs. However, the problem that customer's expectation of service quality is generally anticipated with the acceptable levels of service quality in the service providers like private financial institutions. Using the SERVQUAL model, customers' expectations against their perceptions of this kind of service quality at any financial institute like a bank can be evaluated.

"SERVQUAL" is a service research instrument that measures customer satisfaction with various aspects of service quality (Mulder, P., 2018). SERVQUAL is a frequently used approach to measure service quality which compares 
customers' expectations before a service encounter and their perceptions of the actual service delivered (Gronroos. 1982). It has five generic dimensions: Reliability to perform the promised service dependably and accurately; Responsiveness to provide prompt service; Empathy for caring and individualized attention to customers; Assurance of knowledge and courtesy of employees and their ability to inspire trust and confidence; and Tangibles includes physical facilities, equipment and appearance of personnel (Van Iwaarden, J., van der Wiele, T., Ball, L., and Millen, R., 2003). Other than SERVQUAL model, the "GAP" model of service quality also offers an integrated view of the consumer-company relationship (Zeithaml, V.A., and Bitner, M.J., 1996).

The scope of this study is confined to the Dhaka City of Bangladesh where the survey was conducted on the customers who already open an account in any form at the private financial institute (bank) and do the transaction in different branches of the same bank. In Bangladesh, not much study has been conducted to measure the banking service quality SERVQUAL model. The study information could assist in improving the service quality of banking services by identifying the gaps in service quality. Therefore, the study aims to measure the customers' expectation levels of service quality in the private financial institute (bank) and their perceptions of the service quality, to determine the gap between customers' expectations and perceptions on the same service quality including the factors that contributed to those gaps.

\section{Methodology}

This is a descriptive type of research that briefly revealed the gaps between levels of customers' expectations and perception of service quality in the bank. The target population was different types of male-female bank account holders. Primary and Secondary data was required for the analysis. Primary data was collected through a face-toface interview using structured pretested questionnaire. The survey was conducted based on Non-Probability Sampling techniques. Fifty customers from the bank have been chosen conveniently for interview. The survey was conducted as the part of an assignment that fulfilled the partial requirement of the Master's level course. The natures of questions used were mainly simple dichotomy with few determinant-choice questions and used level measuring rating scale. Some secondary data was collected from several published materials. Through SERVQUAL model, several statements measure the performance across five dimensions, using a five-point Likert scale measuring both customer expectations and perceptions (Gabbie, O. and O'Neill, M.A., 1996). Using SPSS software, analyses were done with different types of statistical tools including some mathematical calculations. Results are presented through tables, graphs and charts.

\section{Results}

It can be seen in the Table I that among 50 respondents, $44.0 \%$ are service holders, about quarter $(24.0 \%)$ of them are students, $20.0 \%$ are doing business and rest $12.0 \%$ are involved with other earning activities. In the same table, it can be seen that more than two-thirds (68.0\%) are male and rest $32.0 \%$ are female respondents. About $38.0 \%$ respondents are in the middle age group (36-45 years) which followed by near to one-quarters $(24.0 \%)$ of the respondents are in the age ranges from 25 to 35 years, $18.0 \%$ of respondents are in the young age group, i.e. under 25 years of age. About $12.0 \%$ of respondents are above 50 years of age and another $8.0 \%$ are in the group of $46-$ 50 years. The respondent holds multiple types of accounts. Majority (68.0\%) of the respondents have a Savings account, which is followed by the Current and Fixed deposit type of account (each 40.0\%). (Table 1).

Table 1. Survey respondent's profile

\begin{tabular}{lcc}
\hline Respondent's Characteristics & Frequency & Percentage \\
\hline Occupation & & \\
Service & 22 & 44.0 \\
Business & 10 & 20.0 \\
Student & 12 & 24.0 \\
Others & 6 & 12.0 \\
Gender & & \\
Male & 34 & 68.0 \\
\hline
\end{tabular}




\begin{tabular}{lcc}
\hline Female & 16 & 32.0 \\
Age (years) & & \\
$<25$ & 9 & 18.0 \\
$25-35$ & 12 & 24.0 \\
$36-45$ & 19 & 38.0 \\
$46-50$ & 4 & 8.0 \\
$>50$ & 6 & 12.0 \\
Account type* & & \\
Current & 20 & 40.0 \\
Savings & 34 & 68.0 \\
Fixed Deposit & 20 & 40.0 \\
Others & 3 & 6.0 \\
\hline Totis & ( 50.0 \\
\hline
\end{tabular}

Total $=50 ; *$ Multiple responses

Table 2 shows the respondents' level of expectation and perception in regard to five different SERVQUAL dimensions considering various statements. In the reliability dimension, the majority (highest $84 \%$ and lowest $60 \%$ ) of the respondents expected that the bank keeps promise, as usual, the problem will be solved sincerely, perform services from the beginning, keep promises like excellent bank and maintain error-free records. But respondents ' perceived reliability dimension varied with all agreeable statements and prevailing lower proportion (highest $82 \%$ and lowest $46 \%$ ). This is revealed from the same table that the respondent's expectation and perceived level varied widely (higher expectation vs. lower perception) with all agreeable statements under responsiveness, empathy, assurance and tangible dimensions. The proportion of these variation ranges from $60 \%$ to $80 \%$.

The expected and perceived SERVQUAL examines different statements through five dimensions of service quality: Reliability, Responsiveness Assurance, Empathy and Tangible. Table 2 analyzed the customers' (respondents') expectation and perception towards the services levels of bank on the scale 1 to 5 with 22 statements in five dimensions.

Table 2. Expectation and perception on SERVQUAL dimensions

\begin{tabular}{lcccccc}
\hline \multirow{2}{*}{ Statement (n=50) } & \multicolumn{3}{c}{ Expectation (\%) } & \multicolumn{3}{c}{ Perceived (\%) } \\
\cline { 2 - 7 } & Agree & Neutral & Disagree & Agree & Neutral & Disagree \\
\hline Reliability & 88.0 & 8.0 & 4.0 & 82.0 & 10.0 & 8.0 \\
1. Keep promise as usual & 86.0 & 14.0 & 0.0 & 72.0 & 22.0 & 6.0 \\
2. Solve problem sincerely & 84.0 & 12.0 & 4.0 & 72.0 & 22.0 & 6.0 \\
3. Perform service from beginning & 76.0 & 18.0 & 6.0 & 58.0 & 34.0 & 8.0 \\
4. Keep promise as excellent banks & 60.0 & 20.0 & 20.0 & 46.0 & 32.0 & 22.0 \\
5. Error free records as excellent banks & & & & & & \\
Responsiveness & 80.0 & 14.0 & 6.0 & 76.0 & 18.0 & 6.0 \\
1. Inform exact services time & 74.0 & 22.0 & 4.0 & 62.0 & 34.0 & 4.0 \\
2. Prompt service & 60.0 & 32.0 & 8.0 & 60.0 & 38.0 & 2.0 \\
3. Constant helping attitude & 62.0 & 28.0 & 10.0 & 66.0 & 22.0 & 12.0 \\
4. Never show busyness to respond & & & & & & \\
Empathy & 74.0 & 16.0 & 10.0 & 58.0 & 32.0 & 10.0 \\
1. Give individual attention & & & & & & \\
2. Customers' convenient operating & 74.0 & 20.0 & 6.0 & 62.0 & 34.0 & 4.0 \\
hours & 74.0 & 16.0 & 10.0 & 56.0 & 32.0 & 12.0 \\
3. Give customers personal service & 70.0 & 20.0 & 10.0 & 54.0 & 32.0 & 14.0 \\
4. Customers' best interest at heart & 70.0 & 18.0 & 12.0 & 50.0 & 30.0 & 20.0 \\
5. Understand customers' specific needs & & & & & & \\
Assurances & 80.0 & 12.0 & 8.0 & 68.0 & 26.0 & 6.0 \\
1 Confidence in employees' behavior & 78.0 & 16.0 & 6.0 & 78.0 & 16.0 & 6.0 \\
2. Feel safe transactions & & & & &
\end{tabular}




$\begin{array}{lcccccc}\text { 3. Consistently courteous to customers } & 68.0 & 24.0 & 8.0 & 64.0 & 22.0 & 14.0 \\ \text { 4. Able to answer customers' questions } & 66.0 & 22.0 & 12.0 & 62.0 & 22.0 & 16.0 \\ \text { Tangible } & & & & & & \\ \text { 1. Have modern equipment } & 78.0 & 18.0 & 4.0 & 68.0 & 24.0 & 8.0 \\ \text { 2. Appealing physical facilities } & 80.0 & 16.0 & 4.0 & 58.0 & 32.0 & 10.0 \\ \text { 3. Neat appearance of employees } & 76.0 & 14.0 & 10.0 & 56.0 & 26.0 & 18.0 \\ \text { 4. Appealing promotional materials } & 60.0 & 26.0 & 14.0 & 58.0 & 30.0 & 12.0\end{array}$

Note: Five points scale (strongly agree to strongly disagree) merged into 3 (agree, neutral and disagree)

In Table 3 the Gap Score for each dimension is calculated by subtracting the average perception score from the average expectation score. Reliability in the service quality dimensions means the ability to perform the services accurately and dependably. The reliability dimension shows that the average gap ranges from 0.8 to 1.30 which implies that the customer is not getting the service accurately from the bank and dependably enough to match their expectation. The service provided is below their expectation and thus making them much dissatisfied. The role of Responsiveness is that the willingness to help customers and provide a prompt service, which shows that the average gap ranges from 0.9 to 1.2 . The bank has a fair lot to do to improve the service provided in these dimensional aspects to meet the customers' expectations and satisfy their customers. Empathy contains the issues of access, communication, and understanding of the customer. The average gap shows that the variation $(0.6$ to $1.2)$ is still existing which indicates the caring individual attention given is not meeting even the minimum expectation by the employees of the bank. Assurance is a combination of competence, courtesy, credibility, and security. The result shows that the lowest and highest gap is 0.8 and 1.1, respectively. This implies that the knowledge and courtesy of the bank's employees and their ability to convey trust and confidence are not up to the mark. The customers do not feel adequately confident and trust the bank to provide service to their expectations. The Tangible part of the service quality dimension is the appearance of physical facilities, equipment, personnel, and information materials. The gap between average scores of expectation and perception are also pronounced ( 0.9 to 1.1). This implies that there is a gap in the appearance of the bank visually. The customer's highest expectation was that the bank will be equipped and furnished with modern equipment.

The result in the Figure 1 indicates that the overall average expectation for reliability dimension is 4.0 and perception is 3.0. The average gap for reliability dimension between expectation and perception is 1.0. Similarly, these gaps are almost same (nearly 1.0) for other dimensions; responsiveness (3.9 and 2.8), empathy (3.9 and 3.0), assurance (3.9 and 3.0), and tangible (3.9 and 2.9).

Table 3. Gap on average dimension score of expectation and perception

\begin{tabular}{lcccc}
\hline $\begin{array}{l}\text { SERVQUAL } \\
\text { Dimension }\end{array}$ & S. No. & Avg. Score, E & Avg. Score, P & $\begin{array}{c}\text { Gap } \\
\text { (E-P) }\end{array}$ \\
\hline Reliability & & & & \\
& 1 & 4.3 & 3.2 & 1.10 \\
& 2 & 4.2 & 2.9 & 1.30 \\
& 3 & 4.1 & 2.9 & 0.80 \\
Responsiveness & 4 & 3.9 & 3.1 & 0.80 \\
& 5 & 3.5 & 2.7 & 1.00 \\
& 1 & 4.1 & 3.1 & 0.90 \\
Empathy & 2 & 3.9 & 3.0 & 1.20 \\
& 3 & 3.7 & 2.5 & 1.10 \\
& 4 & 3.8 & 2.7 & 1.20 \\
Assurances & 1 & 4.1 & 2.9 & 0.60 \\
& 2 & 4.1 & 3.5 & 0.80 \\
& 3 & 3.9 & 2.9 & 1.00 \\
\hline
\end{tabular}




\begin{tabular}{|c|c|c|c|c|}
\hline & 2 & 4.0 & 3.2 & 0.80 \\
\hline & 3 & 3.8 & 3.0 & 0.80 \\
\hline & 4 & 3.7 & 2.8 & 0.90 \\
\hline \multicolumn{5}{|l|}{ Tangible } \\
\hline & 1 & 4.1 & 3.1 & 1.00 \\
\hline & 2 & 4.0 & 2.9 & 1.10 \\
\hline & 3 & 3.9 & 2.8 & 1.10 \\
\hline & 4 & 3.7 & 2.8 & 0.90 \\
\hline
\end{tabular}

Note: S. No. $=$ Statement number; E=Expectation, $\mathrm{P}=$ Perception

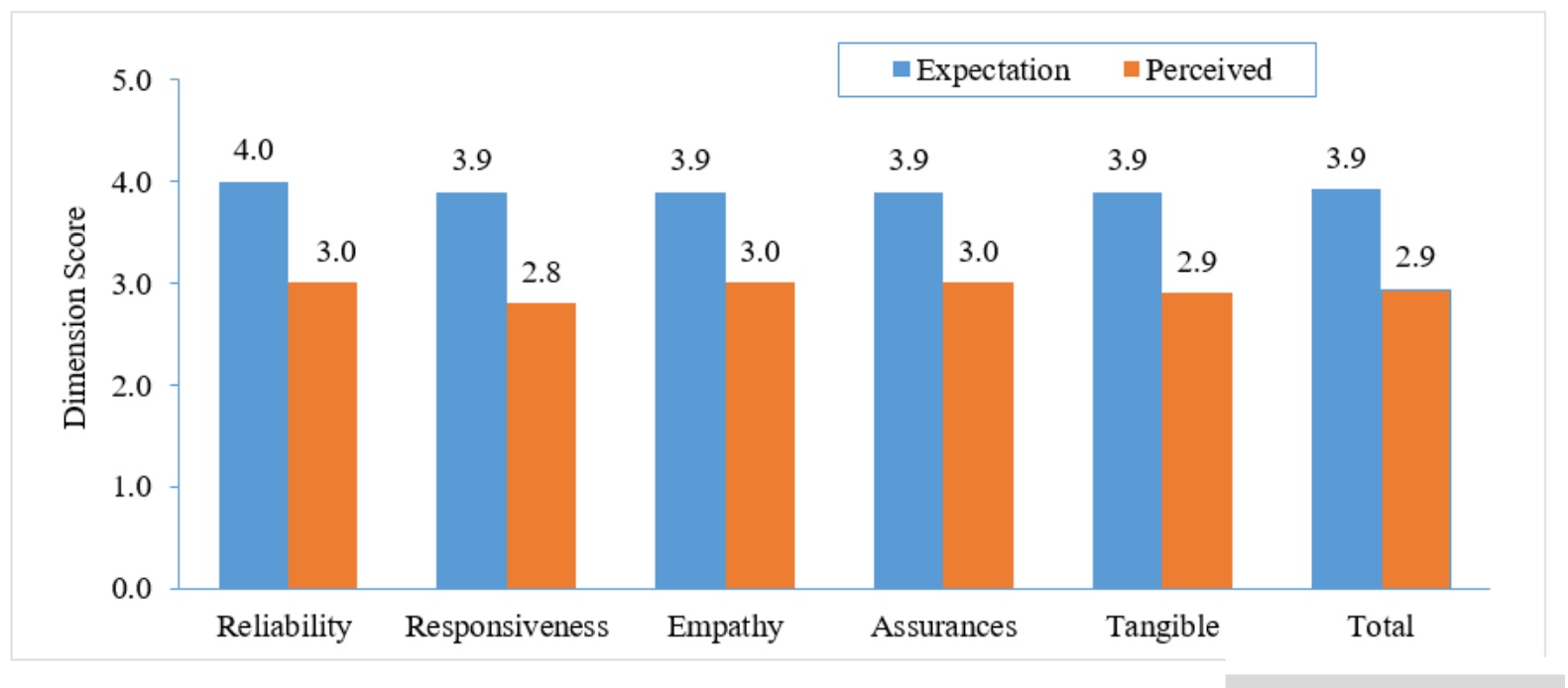

Figure1. Average total score of SERVQUAL dimension.

On an average total score of five SERVQUAL dimensions according to customers' (respondents) expectation and perception levels examined through various statements. The results indicate a total expectation score of 3.9 and a perception score of 2.9. There is a gap of -0.98 between expectation and perception. From the above summary, it is seen that the bank is consistently failing to meet customer (as per responses) expectation in every dimension. As a result, customers may get dissatisfied with the service of the banks in the near future (Figure 1).

\section{Discussions}

The purpose of the study was to assess consumer perceptions and expectations of service quality of banks. A total of 50 respondents were interviewed in different branches of a selected bank located at Dhaka in Bangladesh. SERVQUAL method was used to measure the gap between the expectations of the clients and their perception after receiving the services. Twenty-two service quality-related questions were administered through questionnaire which belongs to five major dimensions. The sample respondents respond to each question in five-point Likert scale.

It was found that clients' expectations were comparatively higher in terms of keeping promises and solving problem sincerely. Other important indicators where clients' expectations were higher are: bank will provide services from the beginning, the bank will inform exact service time, employees will give individual attention to clients, the operating hour will be convenient for the clients, employees will be confident in their behavior, and the bank will have modern equipment. This is also observed that clients' expectation regarding error-free record is the least, which implies that clients are suspicious about banks' ability to maintain error-free records. At the dimension level, this was observed that the clients' value almost equal expectations in all five dimensions.

By examining the perception of clients after receiving actual services from the bank, this is found that there are gaps in expectations and perceptions in all indicators with varying degrees. Among all twenty-two indicators, operating hours for the customers were found to meet the highest satisfaction from the customers. Also, a large 
portion of the respondents perceived that banks keep their promises and also they feel safe about the bank transactions. The highest gaps between expectations and perceptions are observed in terms of sincere problem solving by the bank employees. Clients' perception regarding helping attitude of the bank is found to be lowest.

From the SERVQUAL analysis this study identified various weaknesses in the service provided by the financial institutions in Bangladesh. To improve the quality of service, the financial institutions need to focus on the areas where clients' perceptions are low and where the gap between expectations and perceptions are large.

It can be concluded from the study results that the level of respondents' expectations on the service quality in the bank was higher than they perceived for the same. The respondents who are maintaining different transactions with the financial institution had expectation towards quality services were not in the acceptable levels compared to other excellent banks. Usually, a respondent expected a high level of service quality from the bank, if not met that expectation may result in respondents' dissatisfaction. Under these circumstances, the private financial institutes may lose their customers in the competitive market. The service provided by the private financial institutes, however, should be maintained at a minimum level of customers' expectations whatever they perceived later. If the minimum level of customer satisfaction can be maintained by these financial institutes, their customers will not dissatisfy and retain a longer time with bank services. Also, this can be concluded that acceptable levels of service quality at the bank is still higher as indicated through the gaps between respondents' expectation and perceived level. The private financial institute like the bank should design service standards that promote reliability to customers, consistency in service delivery and give more responsive understanding to their customers and their level of service quality should be improved further.

\section{Acknowledgment}

The researcher gratefully acknowledges the role of Bangladesh University of Professionals (BUP), for giving me the scope to do this research. I convey my sincere gratitude to Mr. Mehedi Hasan for guiding me throughout this research work and for his continuous support since the inception of the research. I would like to send my heartiest regards to Dr. B. Chandrachoodan Nair for his inputs in the manuscript preparation including comments and suggestions in this research.

\section{References}

Gagliano, K.B. \& Hathcote. J (1994). Customer Expectations and Perceptions of Service Quality in Retail Apparel Specialty Stores. Journal of Services Marketing, Volume.8, Issue No 1, pp. 60-69.

Zeithaml, V.A. and Bitner, M.J. (1996). Services Marketing. McGraw-Hill, New York.

Mulder, P. (2018). SERVQUAL Model. Retrieved from Tools Hero: https://www.toolshero.com/qualitymanagement/servqual-model/.

Gronroos. (1982). A Service Quality Model and its Marketing Implications. European Journal of Marketing Volume 18, Issue 4.

Van Iwaarden, J., van der Wiele, T., Ball, L., and Millen, R. (2003). Applying SERVQUAL to web sites: An exploratory study, International Journal of Quality \& Reliability Management Vol.20, No.8, pp. 919-935.

Gabbie, O. and O'Neill, M.A. (1996). SERVQUAL and the Northern Ireland hotel sector: A comparative analysis-Part 1, Managing Service Quality, Vol.6, No.6, pp. 25-32. 